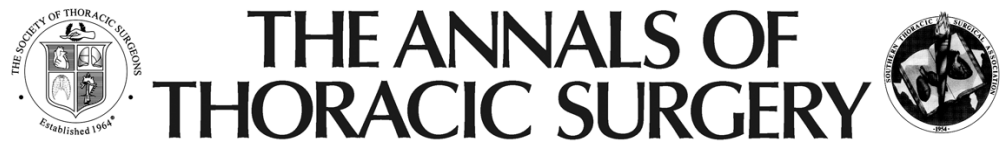

\section{Relevance of Lymph Node Micrometastases in Radically Resected Endobronchial Carcinoid Tumors}

Tommaso Claudio Mineo, Gianluca Guggino, Davide Mineo, Gianluca Vanni and Vincenzo Ambrogi

Ann Thorac Surg 2005;80:428-432

The online version of this article, along with updated information and services, is located on the World Wide Web at:

http://ats.ctsnetjournals.org/cgi/content/full/80/2/428 


\title{
Relevance of Lymph Node Micrometastases in Radically Resected Endobronchial Carcinoid Tumors
}

\author{
Tommaso Claudio Mineo, MD, Gianluca Guggino, MD, Davide Mineo, MD, \\ Gianluca Vanni, MD, and Vincenzo Ambrogi, MD \\ Division of Thoracic Surgery, Tor Vergata School of Medicine, Policlinico Tor Vergata University, Rome, Italy
}

Background. Endobronchial carcinoids may recur even if radically resected. This retrospective study investigates the clinical and prognostic relevance of lymph node micrometastasis in these neoplasms.

Methods. Fifty-five patients underwent standard anatomic resection (lobectomy or pneumonectomy) with systematic routine (hilar and mediastinal) lymphadenectomy. After an evaluation of conventional prognostic factors, we reanalyzed lymph nodes of pN0 patients for micrometastasis using immunohistochemistry (anti-cytokeratin AE1/AE3 and anti-chromogranin A antibodies).

Results. We performed 9 pneumonectomies, 41 lobectomies, and 5 bilobectomies. Histologic examination showed $47(85 \%)$ typical carcinoid and $8(14.5 \%)$ atypical. Twelve patients were pN1 (8 typical, 4 atypical); after reanalysis another 8 revealed micrometastasis, $6 \mathrm{N1}$ micrometastasis (5 typical, 1 atypical), and 2 N2 micrometastasis (2 atypical), increasing subjects with nodal involvement (pN1 and $\mathrm{N}$ micrometastasis) from $12 \mathbf{( 2 1 . 8 \% )}$ to $20(36.4 \% ; p=0.01)$. Micrometastases were more frequent in atypical carcinoids $(p=0.002)$. Local recur-

$\mathrm{C}$ arcinoid tumors are rare, low-grade malignant neoplasms derived from neoplastic proliferation of the diffused neuroendocrine cells throughout the body. In $3.5 \%$ of cases they develop in the lung, where in the $80 \%$ of cases that are endobronchial, they arise from the mainstem bronchus or the proximal portion of the lobar bronchi [1, 2]. In 1999 the World Health Organization [3, 4] proposed a new classification based on histologic criteria considering two different subtypes: typical (TC) and atypical (AC) carcinoid. Typical carcinoids are more frequent and benign than ACs, although both can metastasize to regional lymph nodes or distant organs [3], influencing survival and therapeutic strategy. At present, surgery is the treatment of choice, although ideal extension of resection and opportunity of lymphadenectomy are still controversial $[5,6]$.

Accepted for publication Feb 28, 2005.

Address reprint requests to Dr Mineo, Cattedra di Chirurgia Toracica, Università Tor Vergata, Policlinico Universitario di Tor Vergata, Vle Oxford, 81, Rome 00133, Italy; e-mail: mineo@med.uniroma2.it. rence developed in $3(5.4 \%)$ patients: 2 pN1 (1 typical, 1 atypical) and 1 N1-micrometastasis (1 typical). Distant relapse occurred in $2(3.6 \%)$ patients, both $\mathrm{N} 2$ micrometastasis ( 2 atypical). After reanalysis, recurrence rate in patients with nodal disease increased from $16.7 \%$ to $25 \%$ $(p=0.01)$. All patients with recurrence died: all had pN1 or $\mathbf{N}$ micrometastasis. No patient confirmed as N0 had recurrence. Only histologic pattern and node status significantly influenced disease-free ( $p=0.002$ and $p=0.05$ ) and overall survivals ( $p=0.02$ and $p<0.001$ ), respectively. Micrometastasis worsen both disease-free $(p<$ $0.0001)$ and overall $(p<0.001)$ survival rates at 5 and 10 years.

Conclusions. Routine systematic lymphadenectomy with immunohistochemical detection of lymph node micrometastasis contributes to identification of a larger population at risk with a higher recurrence rate, allowing a more accurate staging of endobronchial carcinoids.

(Ann Thorac Surg 2005;80:428-33) (C) 2005 by The Society of Thoracic Surgeons

Lymph node metastases represent the most accurate prognostic factor in patients undergoing complete surgical resection for lung cancer [7]. Recently, individual or clustered tumor cells in lymph nodes, defined as micrometastasis and previously undetectable with conventional histopathologic techniques, have now been revealed by immunohistochemistry using specific monoclonal antibodies [8]. Presence of lymph node micrometastasis has been associated with reduced diseasefree survival in non-small-cell lung cancer [9].

To date, the impact of lymph node micrometastasis in endobronchial carcinoid tumors has not yet been investigated. We reviewed the records of 55 patients who underwent radical surgery with systematic lymphadenectomy and reanalyzed the previously negative lymph nodes for occult metastatic tumor cells.

Our purpose was to evaluate the impact of lymph node micrometastases on disease-free and overall survival after radical surgical procedures for endobronchial carcinoids. Correlations with conventional prognostic factors were also investigated to detect a new category of patients at risk of recurrence. 


\section{Material and Methods}

\section{Study Design}

We retrospectively reviewed 55 consecutive patients operated on in our institution between 1980 and 2000 for endobronchial carcinoid tumors. There were 33 male $(60 \%)$ and 22 female $(40 \%)$ patients with a mean age of $46.9 \pm 16.8$ years (range, 9 to 82 years). Study inclusion criteria required sessile, central, and endoluminal mass, visualized by bronchoscopy (Fig 1) and treated by radical surgery. This implies a standard anatomic resection (lobectomy or pneumonectomy) with systematic routine hilar and mediastinal lymphadenectomy. All patients underwent preoperative pulmonary and cardiac evaluation.

Presenting symptoms were recurrent pulmonary infections in $25(45.4 \%)$ cases, major or minor hemoptysis in 12 $(21.8 \%)$, dyspnea in $7(12.7 \%)$, and cough in $6(10.9 \%)$, whereas in $5(9 \%)$ asymptomatic subjects, tumors were detected on occasional chest roentgenograms. Length of symptoms before presentation varied from 1 to 5 years. No patient presented the carcinoid syndrome.

All patients were evaluated by total body computed tomography. No clinical evidence of N2 disease was found so that mediastinoscopy was never accomplished.

Fiberoptic bronchoscopy was performed before surgery in all patients. In 22 cases we also performed rigid bronchoscopy with biopsy, and diagnosis was accurate in 10. No biopsy was complicated by relevant hemorrhage.

Intraoperative frozen-section analysis of resection margins was performed in all patients, and none disclosed viable residual of disease. Tumors were classified according to the classification by Travis and colleagues [3], and were retrospectively reviewed according to the World Health Organization and International Association for the Study of Lung Cancer criteria for neuroendocrine neoplasms [4]. Staging was performed according to the 1997 revisions in the International System for Staging Lung Cancer [9].

Conventional prognostic factors considered were age, sex, symptoms, tumor size, location, surgical procedure, and World Health Organization classification.

Hospital mortality included all intraoperative and 30day postoperative deaths. Follow-up ranged from 16 months to 25 years (mean, $150 \pm 83$ months), and it was carried out by an outpatient annual visit including fiberoptic bronchoscopy and total body computed tomography scan until the patient's death.

\section{Lymph Node Reanalysis}

We reconsidered hilar and mediastinal lymph nodes previously negative ( $\mathrm{pN} 0$ ) by conventional histopathologic technique and reanalyzed for occult metastatic tumor cells by immunohistochemistry with AE1/AE3 anti-cytokeratin and anti-chromogranin A monoclonal antibodies. The former specifically recognizes the epithelial normal and neoplastic cells, whereas the latter is widely used as a general neuroendocrine cell marker.

Immunohistochemical examinations were performed by a standard avidin-biotin peroxidase technique, using formalin-fixed, paraffin-embedded material [10]. Five $4-\mu \mathrm{m}$ slices of single paraffin-embedded lymph node

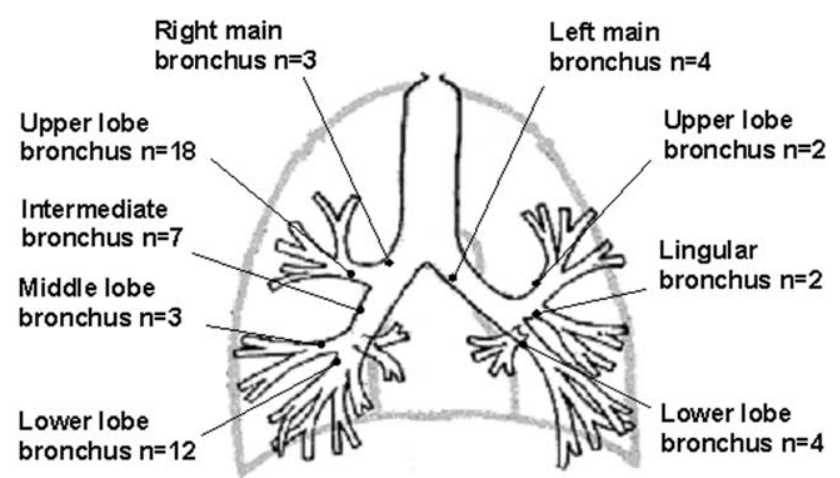

Fig 1. Location of endobronchial carcinoid tumors.

sections were transferred on glass slides. Monoclonal antibodies to wide-spectrum cytokeratin (AE1/AE3, dilution 1:50; Dako Corporation, Carpinteria, CA) and chromogranin (CgA, dilution 1:100, Dako Corporation) were used. Hematoxylin and eosin was used as a routine counterstain. A positive staining within the section of the lymph node was accepted as evidence of micrometastatic tumor cells.

Micrometastasis is defined as tumor cells implantation of a size of $2 \mathrm{~mm}$ or less in the organ involved with extravasation, proliferation, and stromal reaction often detected by immunohistochemistry and not previously evidenced by traditional histopathologic staining [11].

\section{Statistical Analysis}

Patients were evaluated for demographic, surgical, and pathologic variables. The distributions of these variables were compared using the $\chi^{2}$ test or Fisher's exact test for discrete variables and unpaired Student's $t$ test for continuous variables. Quantitative data were expressed as the mean \pm standard deviation. Survival and tumor recurrences were measured from the date of operation. Overall and disease-free survivals were calculated by the Kaplan-Meier method, and the log-rank test was used for comparisons [12]. A $p$ value less than or equal to 0.05 was considered significant. All data were analyzed by Systat 9.0 (SPSS, Inc, 1999, Chicago, IL).

\section{Results}

Clinical features of the study group are summarized in Table 1. Pulmonary resections included 9 (16.4\%) pneumonectomies (5 right, 4 left), 41 (74.5\%) lobectomies (18 right superior, 12 right inferior, 3 middle, 2 left superior, 4 left inferior, and 2 lingula), and 5 (9.1\%) bilobectomies. Pneumonectomy was necessary because of severe damage of the obstructed lung $(n=5)$ and positive resection margins $(n=4)$. There were no postoperative major complications or deaths. All patients had a complete mean follow-up period of $150.4 \pm 86.1$ months (range, 16 to 302 months).

Of 55 carcinoid tumors, $47(85.5 \%)$ were TC and 8 $(14.5 \%)$ AC. Twelve patients were staged $\mathrm{pN} 1$ and 43 pN0. When we reanalyzed lymph nodes of $\mathrm{pN} 0$ patients, $8(8$ of $43,18.6 \%)$ revealed nodal micrometastasis (Nmi), 6 
Table 1. Study Group: Clinical Features and Significances According to Subtypes

\begin{tabular}{|c|c|c|c|}
\hline Variable & $\begin{array}{c}\text { Typical } \\
\text { Carcinoids } \\
(\mathrm{n}=47)\end{array}$ & $\begin{array}{c}\text { Atypical } \\
\text { Carcinoids } \\
(\mathrm{n}=8)\end{array}$ & $p$ Value \\
\hline Mean age (y) & $47 \pm 17.3$ & $46 \pm 15.3$ & 0.1 \\
\hline \multicolumn{4}{|l|}{ Sex } \\
\hline Male & 27 & 6 & \multirow[t]{2}{*}{0.3} \\
\hline Female & 20 & 2 & \\
\hline \multicolumn{4}{|l|}{ Side of operation } \\
\hline Right & 37 & 6 & \multirow[t]{2}{*}{0.8} \\
\hline Left & 10 & 2 & \\
\hline \multicolumn{4}{|l|}{ Surgical Procedure } \\
\hline Pneumonectomy & 7 & 2 & \multirow[t]{7}{*}{0.4} \\
\hline Lobectomy & 35 & 6 & \\
\hline Upper lobectomy & 18 & 2 & \\
\hline Lower lobectomy & 15 & 1 & \\
\hline Middle lobectomy & 1 & 2 & \\
\hline Lingulectomy & 1 & 1 & \\
\hline Bilobectomy & 5 & $\ldots$ & \\
\hline \multicolumn{4}{|l|}{ Stage } \\
\hline I & 35 & 3 & \multirow[t]{2}{*}{0.04} \\
\hline II-IV & 12 & 5 & \\
\hline \multicolumn{4}{|l|}{ Tumor stage } \\
\hline pT1 & 39 & 6 & \multirow[t]{2}{*}{0.6} \\
\hline pT2 & 8 & 2 & \\
\hline \multicolumn{4}{|l|}{ Nodal stage } \\
\hline pN0 & 39 & 4 & \multirow[t]{5}{*}{0.002} \\
\hline N0mi & 34 & 1 & \\
\hline $\mathrm{N} 1 \mathrm{mi}$ & 5 & 1 & \\
\hline $\mathrm{N} 2 \mathrm{mi}$ & $\ldots$ & 2 & \\
\hline $\mathrm{pN} 1$ & 8 & 4 & \\
\hline \multicolumn{4}{|l|}{ Recurrences } \\
\hline Local & 2 & 1 & \multirow[t]{5}{*}{0.001} \\
\hline pN1 & 1 & 1 & \\
\hline N1mi & 1 & $\ldots$ & \\
\hline Distant & $\ldots$ & 2 & \\
\hline $\mathrm{N} 2 \mathrm{mi}$ & & 2 & \\
\hline
\end{tabular}

$\mathrm{mi}=$ micrometasis.

$\mathrm{N} 1 \mathrm{mi}$ and $2 \mathrm{~N} 2 \mathrm{mi}$, significantly increasing the number of subjects with nodal involvement ( $\mathrm{pN} 1$ and $\mathrm{Nmi}$ ) from 12 $(12$ of $55,21.8 \%)$ to 20 (20 of $55,36.4 \% ; p=0.01)$.

In the TCs, $8(17.0 \%)$ patients were $\mathrm{pN} 1$; in the remaining 39 subjects staged $\mathrm{pN} 0,5(12.8 \%)$ revealed N1mi (1 pT1, 1 pT2, 3 pT3). In the ACs, $4(50 \%)$ patients were $\mathrm{pN} 1$; in the remaining $4 \mathrm{pN0}$ subjects, $3(75 \%)$ disclosed micrometastasis: 1 N1mi (pT3) and 2 N2mi (1 pT1, 1 pT3). A significantly higher frequency of lymph node micrometastasis was evidenced in ACs with respect to TCs (37.5\% versus $10.6 \% ; p=0.002)$. No further relationship was demonstrated between the presence of micrometastasis and main clinical factors, namely tumor stage and size (data not showed).

\section{Disease-Free Survival}

Recurrent disease was evident in $5(9.1 \%)$ patients after a postoperative mean interval of $90 \pm 32.4$ months. Two were pN1 ( 2 of $12,16.7 \%$ ), whereas 3 pN0 ( 3 of $43,7 \%$ ) after reanalysis were $1 \mathrm{~N} 1 \mathrm{mi}$ and $2 \mathrm{~N} 2 \mathrm{mi}$, significantly increasing the recurrence rate in patients with nodal disease from $16.7 \%$ to $25 \%$ ( 5 of $20 ; p=0.01$ ). None of the patients confirmed as N0 had recurrence.

Local recurrence occurred in $3(5.4 \%)$ patients, 2 pN1 (1 TC and $1 \mathrm{AC}$ ) and $1 \mathrm{~N} 1 \mathrm{mi}$ (1 TC), all sited in the proximity of the bronchial stump. One patient underwent endobronchial laser resection after a postoperative interval of 130 months, whereas the other 2 were treated by completion pneumonectomy after 90 and 100 months.

Distant relapse occurred in $2(3.6 \%)$ patients, both $\mathrm{N} 2 \mathrm{mi}(2 \mathrm{AC})$ and were localized in liver $(\mathrm{n}=2)$, bone $(\mathrm{n}$ $=1)$, and breast $(n=1)$. Both patients were treated by chemotherapy (cisplatinum $45 \mathrm{mg} / \mathrm{m}^{2}$ on days 2 and 3 and etoposide $100 \mathrm{mg} / \mathrm{m}^{2}$ on days 1 to 3 for six cycles with an interval of 4 weeks) after a postoperative interval of 40 and 90 months.

Among conventional prognostic factors, only histologic pattern (TC or AC) and nodal status ( $\mathrm{pN} 0$ or $\mathrm{pN} 1$ ) significantly influenced disease-free survival ( $p=0.002$ and $p=0.05$, respectively).

Disease-free survival rate of patients with nodal involvement ( $\mathrm{pN} 1+\mathrm{Nmi}$ ) was $83.3 \%$ at 5 years and $55.6 \%$ at 10 in comparison to $100 \%$ without ( $p<0.0001$; Fig 2 ).

\section{Overall Survival}

Seven patients $(12.7 \%)$ died within a mean period of $98 \pm$ 34.9 months after surgery. Four were pN1 (4 of 12, 33.3\%) whereas 3 pN0 ( 3 of $43,7 \%$ ) resulted at reanalysis as 1 $\mathrm{N} 1 \mathrm{mi}$ and $2 \mathrm{~N} 2 \mathrm{mi}$. All 5 patients with recurrence died; the remaining 2 patients, both $\mathrm{pN} 1$, died without evidence of recurrence. Three patients with micrometastasis had re-

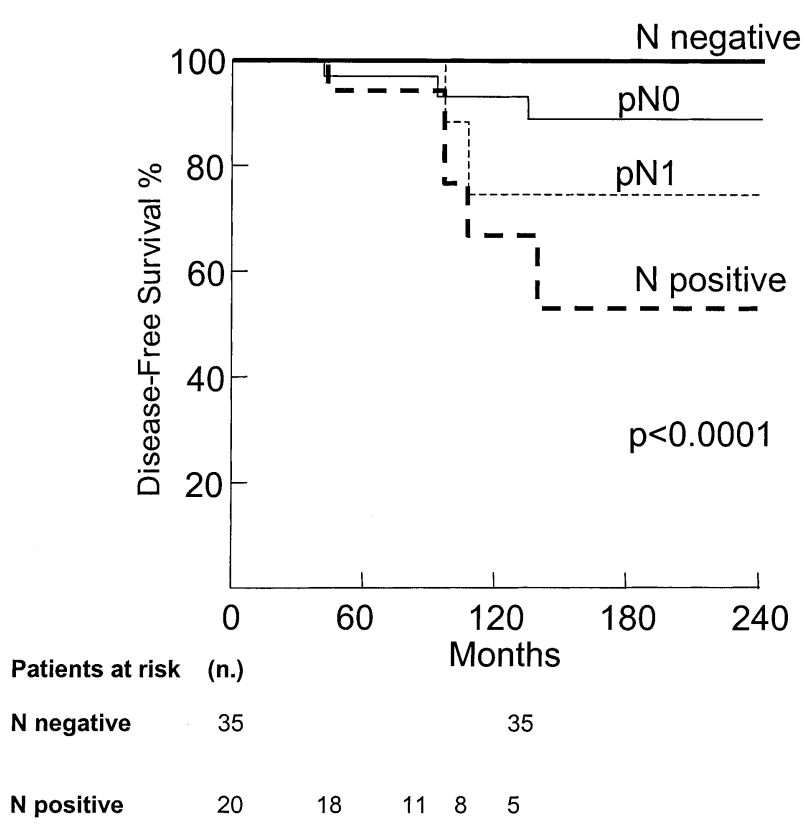

Fig 2. Kaplan-Meier disease-free survival and log-rank test for patients with positive $(N$ positive $=p N 1+N m i)$ and negative $(N$ negative $=\mathrm{NO}$ ) lymph node micrometastasis. Survivals with traditional pathologic nodal staging ( $p N O$ and $p N 1$ ) are also reported. 
currence ( 3 of $8,37.5 \%$ ) and died. All patients confirmed as N0 at reanalysis survived.

Four TC patients ( 4 of 47, 8.5\%) died, all for reasons not directly related to the primary disease, within a mean period of $104 \pm 35$ months. One N1mi patient had a second local recurrence 23 months after endobronchial laser resection and was retreated by laser resection but died after 10 months of acute myocardial infarction. One pN1 patient died of massive pulmonary embolism 50 months after completion pneumonectomy. The remaining 2 patients, both $\mathrm{pN} 1$, died after 68 and 73 months of pulmonary failure.

Three AC patients ( 3 of $8,37.5 \%$ ) died of disease after local $(1 \mathrm{pN} 1)$ and distant $(2 \mathrm{~N} 2 \mathrm{mi})$ recurrences, within a mean period of $85.5 \pm 40$ months.

Among conventional prognostic factors, only histologic pattern (TC or AC) and nodal status ( $\mathrm{pN} 0$ or $\mathrm{pN} 1$ ) significantly influenced overall survival $(p=0.02$ and $p<$ 0.001 , respectively).

Overall survival rate of patients with nodal involvement ( $\mathrm{pN} 1+\mathrm{Nmi}$ ) was $66.7 \%$ at 5 and 10 years in comparison to $96.6 \%$ without ( $p<0.001$; Fig 3 ).

\section{Comment}

Endobronchial carcinoid tumors are considered lowgrade, malignant neoplasms arising from enterochromaffin cells of the bronchial epithelium [2]. Both histologic subtypes, TC and AC, can rarely metastasize to regional lymph nodes or distant organs [3]. These neoplasms are classified in the wide spectrum of neuroendocrine tumors that also include large cell and small cell lung cancer [4].

Radical surgical therapy is widely indicated as the definitive treatment, although there is still much controversy as to the most appropriate extension of resection [5, 13-15] or the opportunity of systematic lymphadenectomy $[16,17]$ to reduce the risk of recurrence.

Conservative surgery (bronchoplastic procedures) reported good disease-free survival in early stage TCs $[6,18]$. Endoscopic laser resection is an alternative technique reserved for palliative bronchial unobstruction in patients not suitable for surgery [17] or for well-pedunculated masses without apparent nodal disease [19].

In our institution, we preferred to approach endobronchial carcinoids, TCs or ACs, as primary bronchogenic carcinoma, performing intentional standard anatomic resection, lobectomy, or pneumonectomy, with systematic routine hilar and mediastinal lymph node dissection.

Despite aggressive surgical resection, local or distant recurrences are present in a consistent percentage of cases. Main series report a rate of recurrence from $2 \%$ to $11.4 \%$ for TCs and from $18.5 \%$ to $50 \%$ for ACs [5, 6, 17, 20-22]. Neither stage I nor pN0 seem to be absolute negative predictors of recurrence. Indeed, in TC pN0 patients, recurrence rate ranges from $2.9 \%$ to $3.2 \%[6,17]$. We also experienced unexpected recurrences in about $7 \%$ of $\mathrm{pN0}$ patients in both subtypes. This observation was the reason of our retrospective study.

We hypothesized that the observed recurrences were probably the result of tumor spread to locoregional

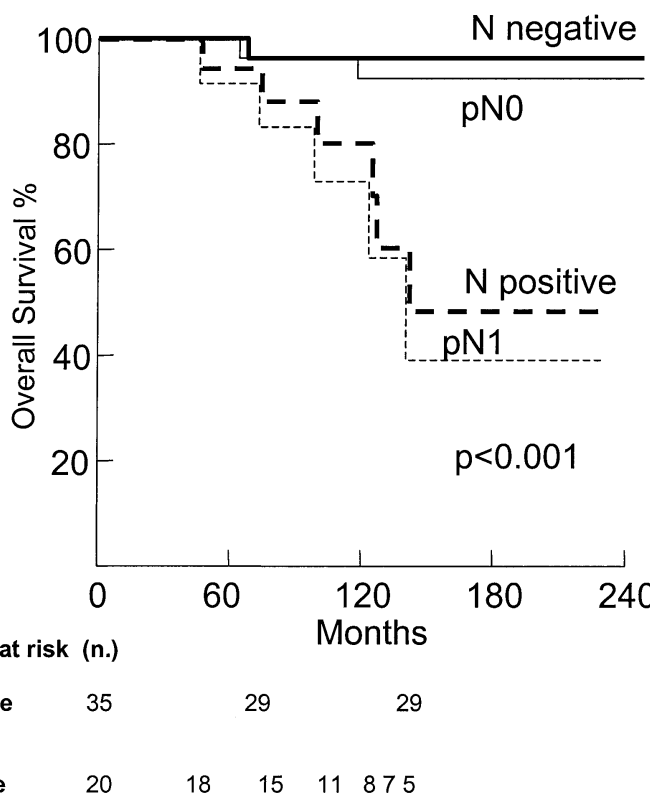

Fig 3. Kaplan-Meier overall survival and log-rank test for patients with $N$ positive ( $p N 1$ and $p N 1+N m i)$ and negative ( $p N O$ and NO) lymph node micrometastasis. Survivals with traditional pathologic nodal staging ( $p N 0$ and $p N 1$ ) are also reported.

lymph nodes before surgery, considering micrometastasis the first step of cancer diffusion [23]. Detection of nodal micrometastasis may allow a more accurate staging of bronchial carcinoids, thus providing a larger number of patients at risk of recurrence.

On the basis of recent advances in immunohistochemical techniques for detection of occult nodal dissemination in lung cancer, we decided to research lymph node micrometastasis in our bronchial carcinoid specimens by using specific neuroendocrine assays. Chromogranin A is a glycoprotein located in the core of secretory granules of neuroendocrine cells, and it is used as general neuroendocrine histologic marker [24]. Cytokeratin is a component of the intermediate filament of the cytoskeleton in epithelial cells and presents high specificity in tumors derived from epithelial and neuroendocrine cells [25].

In our series, only histologic pattern and nodal status proved capable of influencing disease-free and overall survivals. In particular, nodal reanalysis contributed to refine the staging of our patients with 8 new patients with micrometastasis, 2 of which revealed mediastinal involvement. Almost $15 \%$ of the study group was understaged. Moreover, 3 of the 5 patients who had recurrences disclosed micrometastasis, justifying the unexpected recurrences in pN0 patients. Analysis for micrometastases contributes to identification of a larger population at risk with a higher recurrence rate.

Hilar nodal metastases were likely associated with risk of local recurrence, probably owing to the anatomic proximity to the bronchial stump. On the other hand, mediastinal disease, discovered as micrometastasis in 2 AC patients, developed into fatal distant relapse. As non-small-cell lung cancer, mediastinal nodal involve- 
ment may indicate an already disseminated disease. The significantly higher frequency of micrometastases and the more aggressive nodal spread could justify the severe clinical behavior of ACs. Interestingly, nodal micrometastasis was not correlated with tumor stage and size, indicating that even distally located and small masses may metastasize. Therefore, systematic routine lymphadenectomy should be performed in any endobronchial carcinoid patient.

All patients with recurrence died, indicating that the progression of disease is strongly related to a poorer prognosis. Similarly, all patients who died showed either $\mathrm{pN} 1$ or Nmi, evidencing that nodal disease is a highly sensitive negative prognostic factor that could be more accurately detected. Indeed, one quarter of the subjects with nodal disease and one third of those with micrometastases had recurrences and died. On the contrary, none of the N0 patients at reanalysis had a recurrence or died, confirming the predictive value of nodal invasion.

The limitation of our study is mainly because of the relative rarity of the disease that implies the retrospective type of the analysis and justifies the relatively small sample size, especially in the AC group.

In conclusion, the specific immunohistochemical assay is a reliable method to evaluate early lymphatic spread of endobronchial carcinoid tumors. Detection of micrometastases contributes to identifying a larger population of patients at risk of recurrence. Lymph node micrometastases worsen recurrence rate and prognosis with a significant reduction of disease-free and overall survivals. On these bases, systematic lymphadenectomy should be routinely performed, allowing a more accurate staging of these neoplasms and influencing surveillance and therapeutic strategies. In TCs, the presence of N1 involvement may predispose to local recurrence, thus suggesting a more extensive surgical resection or a differentiated follow-up program. Atypical carcinoid tumors have a worse survival rate and tend to develop distant recurrences, justified by the higher probability of N2 micrometastases. Atypical carcinoids or any patient with N2 involvement may configure a high-risk subset in which a stricter clinical follow-up should be carried out and adjuvant chemotherapies hopefully tested.

This study was supported by a grant from the Italian Ministry of Health and Regione Lazio Project "Profilo genetico associato al fenotipo metastatico ed alla prognosi nei tumori polmonari." We thank Davide Mineo, MD, for the statistical review and Gian Luca Vanni, MD, for histological reanalysis.

\section{References}

1. Ganim RB, Norton JA. Recent advances in carcinoid pathogenesis, diagnosis and management. Surg Oncol 2000;9: 173-9.

2. Hasleton P. Histopathology and prognostic factors in bronchial carcinoid tumors. Thorax 1994;49(Suppl):S56-62.

3. Travis WD, Rush W, Flieder DB, et al. Survival analysis of 200 neuroendocrine tumors with clarification of criteria for atypical carcinoid and its separation from typical carcinoid. Am J Surg Pathol 1998;22:934-44.
4. Travis WD, Sobin LH. Histological typing of lung and pleural tumours: international histologic classification of tumours (No. 1). New York: Springer-Verlag, 1999.

5. Marty-Ané CH, Costes V, Pujol JL, et al. Carcinoid tumors of lung: do atypical features require aggressive management? Ann Thorac Surg 1995;59:78-83.

6. Ducrocq X, Thomas P, Massard G, et al. Operative risk and prognostic factors of typical bronchial carcinoid tumors. Ann Thorac Surg 1998;65:1410-4.

7. Izbicki JR, Passlick B, Hosch SB, et al. Mode of spread in the early phase of lymphatic metastasis in non-small-cell lung cancer: significance of nodal micrometastasis. J Thorac Cardiovasc Surg 1996;112:623-30.

8. Passlick B, Izbicki JR, Kubuschok B, et al. Immunohistochemical assessment of individual tumor cells in lymph nodes of patients with non-small-cell lung cancer. J Clin Oncol 1994;12:1827-32.

9. Mountain CF. Revisions in the international system for staging lung cancer. Chest 1997;111:1710-7.

10. Hsu SM, Raine T, Fanger H. Use of avidin-biotin-peroxidase complex $(\mathrm{ABC})$ in immunoperoxidase techniques: a comparison between $\mathrm{ABC}$ and unlabeled (PAP) procedures. J Histochem Cytochem 1981;29:577-80.

11. Hermanek P, Hutter RVP, Sobin LH, et al. Classification of isolated tumor cells and micrometastasis. Cancer 1999;86: 2668-73.

12. Kaplan EL, Meier P. Nonparametric estimation from incomplete observations. J Am Stat Assoc 1958;53:457-81.

13. Ferguson MK, Landreneau RJ, Hazelrigg SR, et al. Longterm outcome after resection for carcinoid tumors. Eur J Cardiothorac Surg 2000;18:156-61.

14. Vadsz P, Palffy G, Egervary M, et al. Diagnosis and treatment of bronchial carcinoid tumors: clinical and pathological review of 120 operated patients. Eur J Cardiothorac Surg 1993;7:8-11.

15. Stamatis G, Freitag L, Greschuchna D. Limited and radical resection for tracheal and bronchopulmonary carcinoid tumor. Report on 227 cases. Eur J Cardiothorac Surg 1990;4:527-32.

16. Thomas CF, Tazelaar HD, Jett JR. Typical and atypical pulmonary carcinoids. Outcome in patients presenting with regional lymph node involvement. Chest 2001;119:1143-50.

17. El Jamal M, Nicholson AG, Goldstraw P. The feasibility of conservative resection for carcinoid tumours: is pneumonectomy ever necessary for uncomplicated cases? Eur J Cardiothorac Surg 2000;18:310-6.

18. Terzi A, Londaroni A, Falezza G, et al. Sleeve lobectomy for non-small cell lung cancer and carcinoids: results in 160 cases. Eur J Cardiothorac Surg 2002;21:888-93.

19. Sutedja TG, Schreurs AJ, Vanderschueren RG, et al. Bronchoscopic therapy in patients with intraluminal typical bronchial carcinoid. Chest 1995;107:556-8.

20. Filosso PL, Rena O, Donati G, et al. Bronchial carcinoid tumors: surgical management and long-term outcome. J Thorac Cardiovasc Surg 2002;123:303-9.

21. Mezzetti M, Raveglia F, Panigalli T, et al. Assessment of outcomes in typical and atypical carcinoids according to latest WHO classification. Ann Thorac Surg 2003;76:1838-42.

22. Kaplan B, Stevens CW, Allen P, et al. Outcomes and patterns of failure in bronchial carcinoid tumors. Int J Radiat Oncol Biol Phys 2003;55:125-31.

23. Osaki T, Oyama T, Gu CD, et al. Prognostic impact of micrometastatic tumor cells in the lymph nodes and bone marrow of patients with completely resected stage I nonsmall-cell lung cancer. J Clin Oncol 2002;20:2930-6.

24. Kimura N, Pilichowska M, Okamoto H, et al. Immunohistochemical expression of chromogranin $\mathrm{A}$ and $\mathrm{B}$, prohormone convertases 2 and 3, and amidating enzyme in carcinoid tumors and pancreatic endocrine tumors. Mod Pathol 2000; 13:140-6.

25. Moll R, Franke WW. Cytoskeletal differences between human neuroendocrine tumors: a cytoskeletal protein of molecular weight 46,000 distinguishes cutaneous from pulmonary neuroendocrine neoplasms. Differentiation 1985;30:165-75. 


\section{Relevance of Lymph Node Micrometastases in Radically Resected Endobronchial Carcinoid Tumors}

Tommaso Claudio Mineo, Gianluca Guggino, Davide Mineo, Gianluca Vanni and Vincenzo Ambrogi

Ann Thorac Surg 2005;80:428-432

$\begin{array}{ll}\begin{array}{l}\text { Updated Information } \\ \text { \& Services }\end{array} & \begin{array}{l}\text { including high-resolution figures, can be found at: } \\ \text { http://ats.ctsnetjournals.org/cgi/content/full/80/2/428 }\end{array} \\ \text { References } & \text { This article cites } 24 \text { articles, } 16 \text { of which you can access for free at: } \\ \text { http://ats.ctsnetjournals.org/cgi/content/full/80/2/428\#BIBL } & \text { This article has been cited by 2 HighWire-hosted articles: } \\ \text { http://ats.ctsnetjournals.org/cgi/content/full/80/2/428\#otherarticles } & \\ \text { Permissions \& Licensing } & \begin{array}{l}\text { Requests about reproducing this article in parts (figures, tables) or } \\ \text { in its entirety should be submitted to: } \\ \text { http://www.us.elsevierhealth.com/Licensing/permissions.jsp or } \\ \text { email: healthpermissions@ elsevier.com. }\end{array} \\ & \begin{array}{l}\text { For information about ordering reprints, please email: } \\ \text { reprints@ elsevier.com }\end{array}\end{array}$

